\title{
A UTOPIA ANTIPOLÍTICA DE NEGRI E HARDT ${ }^{1}$
}

\section{Antonio Claudio Engelke Menezes Teixeira}

atualmente conclui pós-doutorado pelo Programa Nacional de Pós-Doutorado da Coordenação de Aperfeiçoamento de Pessoal de Nivel Superior (PNPD/Capes) em Ciência Política na Universidade do

Estado do Rio de Janeiro (Uerj). Rio de Janeiro, RJ, Brasil. E-mail: antonioengelke@gmail.com

Orcid: 0000-0002-5725-7750

http://dx.doi.org/10.1590/0102-203233/107

Não será preciso realizar um inventário abrangente do atual ideário progressista ${ }^{2}$ para reconhecer que, dadas as circunstâncias crescentemente hostis que envolvem a produção acadêmica e o papel dos intelectuais em esferas públicas capturadas pelo consenso neoliberal, há bons motivos para o ceticismo quanto às possibilidades de tal ideário deflagrar projetos efetivos de transformação política. Pode-se com justeza identificar certa resignação da intelligentsia de esquerda ante o triunfo do pragmatismo, e a consequente perda da sua capacidade de avançar uma imaginação política a um só tempo utópica e crítica (Jacoby, 2001), ou apontar, com ironia mordaz, a aparente preocupação em publicar análises lacanianas de vinhetas da MTV, ou ainda observar com desânimo que, do ponto de vista dos grandes interesses financeiros, melhor uma esquerda debruçada sobre os impasses de identidade de grupo do que sobre questões sindicais (Rorty, Nystrom e Puckett, 2006, p. 54).

${ }^{1}$ Este trabalho foi realizado com apoio da Coordenação de Aperfeiçoamento de Pessoal de Nível Superior (Capes) - Código de Financiamento 001.

2 Penso, por exemplo, na afirmação das políticas da diferença e a ênfase correlata em questões identitárias de representação e reconhecimento de grupos subalternos, tal como aparece no debate entre Nancy Fraser, Axel Honneth e Charles Taylor; na vasta literatura centrada no tema da desigualdade e seus efeitos deletérios, que não cessam de avançar por sobre os escombros do welfare state; ou ainda na teorização de Badiou e seus colegas em favor de uma hipótese comunista, que a despeito da recuperação do lume revolucionário de cariz marxista, falhou em conquistar aderência fora de circuitos acadêmicos restritos. 
Na contramão desse diagnóstico melancólico está a força das ruas, as recentes agitações contra-hegemônicas desafiando o instrumental teórico empregado em sua significação. Em termos substantivos, sobressaem os temas da explosão da desigualdade econômica (Occupy Wall Street), da baixa responsividade do sistema representativo (Indignados) e da demanda pelo direito à cidade (Jornadas de Junho). A denúncia da precarização das condições de vida; a ampliação do hiato socioeconômico dificultando às elites enxergarem-se como participantes da trajetória coletiva que as engloba; o senso de injustiça partilhado por grupos subalternos, que começam a conquistar autoridade discursiva sobre si; o desejo por uma comunalidade capaz de se contrapor às tendências destrutivas do capitalismo tardio; a crítica a uma economia cada vez mais financeirizada e rentista, praticamente livre de controles democráticos; tudo isto esteve posto nessas sublevações. Em comum, a esperança renovada 204 na utopia de uma democracia pós-capitalista que fizesse jus ao demos, uma esperança cuja inspiração fundamental - eis a hipótese que serve de ponto de partida deste trabalho está em larga medida associada à obra de Antonio Negri e Michael Hardt, que logrou colonizar a imaginação do novo ativismo político. Estruturado em torno de noções como império, multidão, trabalho imaterial, comum, biopolítica e general intellect, o vocabulário desses autores espraiou-se para além dos muros da academia, atravessando acampamentos do Occupy Wall Street, fomentando debates entre participantes do 15-M espanhol, inspirando coletivos de ativistas que obtiveram protagonismo durante as Jornadas de Junho.

Negri e Hardt partem do diagnóstico de um império que estaria esvaziando a soberania dos Estados-nação e, com ela, a própria possibilidade da representação política. Articulam tal diagnóstico com a postulação de um sujeito político emergente, uma multidão de singularidades que, impulsionada pela própria forma do trabalho no capitalismo 
cognitivo, teria potencialmente a capacidade de instaurar, por meio da cooperação e da invenção, aquilo que os autores chamam de democracia absoluta. São ideias tão sedutoras quanto problemáticas, e por isso mesmo já amplamente criticadas. Por que, então, mais um trabalho dedicado a examiná-las? Não apenas porque, a despeito das objeções oriundas de círculos acadêmicos, a aposta na multidão continua a capturar a imaginação de boa parte da nova esquerda, mas também porque as críticas de que dispomos até aqui deixaram de observar mais atentamente um ponto importante, qual seja, o exame da utopia que os autores têm em mente.

O trabalho está dividido em duas seções. Na primeira, veremos algumas objeções sociológicas feitas às concepções de Negri e Hardt, mas sem adentrar na controvérsia sobre se os autores teriam interpretado mal as ideias de Marx (Lessa, 2001; Vieira, 2007). Se o que se deseja é interrogar um instrumental teórico no intuito de lhe examinar o rendimento analítico, então investir num exercício exegético que tem por medida única a suposta adequação ao que Marx "realmente" teria dito não é de muita serventia. Em vez disso, argumentaremos que não há conexão intrínseca entre trabalho imaterial, general intellect e emancipação, tal como assumem Negri e Hardt; que o resultado da produção cooperativa do comum permanece sendo sequestrada pelo capital; que, tudo somado, não há indícios de que a conjunção entre trabalho imaterial, comum e multidão possa efetivamente subverter as relações da sociedade com o capital, de modo a dar ensejo a uma política verdadeiramente democrática.

A segunda seção explora criticamente a política da multidão, a quem caberia a tarefa de realizar a democracia absoluta. Tal política revela-se mais uma antipolítica, pois que a própria ontologia da multidão, sua constituição intrinsecamente harmônica ou não-conflituosa, eliminaria de antemão o antagonismo que instaura o político. Observando o caráter 
utópico da proposta negriana, resta evidente que o antagonista cuja eliminação assinalaria o triunfo final da multidão é a forma-estado tal como a conhecemos atualmente. A questão, então, é interrogar que tipo de anarquismo se sucederia à dissolução do Estado como ator político. Negri e Hardt distanciam-se das formulações do anarquismo clássico, mas terminam por repetir-lhe o mesmo erro, qual seja, imaginar que o poder político tenha um exterior a partir do qual poderia ser criticado e superado. Do modo como está colocada na obra dos autores, a ideia de uma democracia absoluta faz crer que, tão logo a forma-estado cesse de existir, o capitalismo viria a desmanchar-se no ar. Negri e Hardt apostam no anarcocomunismo como o desfecho inevitável da utopia que vislumbram, mas esta é uma aposta que só fica de pé se se acreditar que, sem o Estado, o capital perderia sua capacidade de metamorfosear-se, de aproveitar-se de uma nova destruição criativa para refazer a si próprio.

\section{Sociologia: trabalho imaterial e produção do comum}

Ainda na década de 1960, Mario Tronti (1963) falava em "fábrica social", a produção escapando ao espaço físico da fábrica, o social como um todo tornando-se um potencial lócus para a luta, para a resistência. Tronti e o chamado operaísmo italiano buscaram inverter a relação entre o desenvolvimento do capitalismo e a luta dos trabalhadores, avançando um cabedal teórico que oferecia uma perspectiva da evolução tecnológica do capital em termos de uma resposta às lutas do operariado (Mezzadra, 2013). Mas foram seus sucedâneos, marxistas autonomistas reunidos em torno da revista Futur Antérieur, que problematizaram as novas formas de produção realizada fora do âmbito do trabalho assalariado (Trott, 2007,p. 206), conformando uma ampla narrativa sobre o estatuto da exploração e das possibilidades de resistência democrática no contexto do pós-fordismo. Nesse sentido, a obra de Negri e Hardt deve ser lida contra o pano de fundo de sua época; as ideias mais 
otimistas avançadas por livros como Império e multidão são em parte resultado da intensificação das lutas antissistêmicas dos anos 1990 (Dowling, Nunes e Trott, 2007, p. 5).

“Cada período", escrevem Negri e Hardt (2005, p. 191), "é caracterizado por uma ou várias formas comuns que estruturam os diferentes elementos da realidade social e do pensamento". Porque referidas todas a um mesmo Zeitgeist, engenharias institucionais e teóricas partilham de certas características constitutivas em determinado momento histórico; as análises de Foucault do poder disciplinar em escolas, prisões e hospitais são testemunho desse isomorfismo. Tornadas ubíquas no final do século XX, as redes ${ }^{3}$ passaram a delimitar a forma padrão de organização econômica e social dos agentes do capital, os movimentos que lhe opõem resistência, como o Exército Zapatista mexicano, o Movimento dos Trabalhadores Rurais Sem Terra (MST) brasileiro ou o movimento La Via Campesina (Dawson, 2010, p. 17). Em termos epistemológicos, encontramos a ideia de rede na filosofia de Deleuze, na redescoberta da sociologia diferencial de Gabriel Tarde, na força dos "laços fracos" de

\footnotetext{
3 Assumindo a forma de redes, as tecnologias de informação e conhecimento (TIC) tornaram possível a consolidação de um novo tipo de produção social, baseada em propriedades comuns. Obviamente, a produção social de caráter colaborativo não é novidade surgida com o século XX; pensemos na experiência comunal pré-capitalista, ou no trabalho científico, desde sempre exemplos de produção aberta e cooperativa. Mas a partir do momento em que produzir, copiar e compartilhar informações e bens culturais passa a ser uma atividade sujeita a uma facilidade inédita de coordenação de esforços, com custos transacionais desprezíveis, caem os impedimentos que negavam aos indivíduos a possibilidade de se reunirem para juntos darem forma a realizações cujo escopo ultrapassa em muito as possibilidades de cada um deles tomados isoladamente. Ao praticamente zerar os custos de produção e distribuição da informação, e permitir a coordenação de esforços em tempo real, as TIC ofereceram as condições necessárias para que indivíduos pudessem trabalhar de modo a realizar tarefas que antes só poderiam ser levadas a cabo por estruturas verticais, empresas ou burocracias estatais. O reverso da medalha é aquilo que esse elogio da autonomia por meio da tecnologia gostaria de recalcar: à medida em que pavimentam o caminho para o avanço da globalização, as TIC cumprem a função de lhe prover uma aura fetichista.
} 
que falava Granovetter (1973) ou ainda na Teoria do AtorRede de Bruno Latour (2012).

Fiéis à tradição autonomista, Negri e Hardt reinterpretam o conflito de classe no mundo pós-industrial dando ênfase não ao poder do capital, mas à agência de (no jargão deleuziano) singularidades ligadas em rede, cuja atividade inventaria formas produtivas e sociais que o capital tentará conter e capturar, mas sem pleno sucesso. À medida que as mercadorias são mais definidas por componentes de conhecimento e saber, ou de serviços e cuidados, o trabalho necessário à sua produção sofre uma mudança correspondente, tornando-se imaterial. Designando a qualidade distintiva da atividade produtiva numa época em que a comunicação e a informação desempenham papel fundamental no processo produtivo, o trabalho imaterial - a produção de informação e conhecimento, as tarefas analíticas e simbólicas, e a produção e manejo de afetos ${ }^{4}$ - conteria em si potencial liber208 tador, dado que a intimidade com as máquinas do conhecimento e sua captura em redes colaborativas possibilitariam a formação de uma inteligência socializada, o general intellect, cujas iniciativas passariam ao largo do estado e do mercado (Negri e Hardt, 2005). Flexível, móvel, o trabalho imaterial não se limitaria à esfera econômica, mas assumiria a forma de redes baseadas na comunicação, na colaboração e nas relações afetivas, envolvendo a produção da sociedade como um todo. Eis-nos diante de uma produção biopolítica ${ }^{5}$ e, "na medida em que se orienta para a criação de formas de vida

\footnotetext{
${ }^{4}$ Uma distinção se faz necessária aqui. Quando falam em trabalho imaterial, Negri e Hardt não estão se referindo à atividade cognitiva que qualquer trabalho exige; o que está em jogo são os produtos intangíveis dos processos informacionais, simbólicos e afetivos mencionados. Agradeço ao parecerista anônimo por haver chamado minha atenção sobre esse ponto.

${ }_{5}^{5}$ Negri e Hardt partem de Foucault, mas terminam por invertê-lo. O conceito foucaultiano de biopoder referia-se à estratégia de poder desenvolvida a partir do século XVIII para controlar e regular a vida da população. Já o conceito de produção biopolítica de Negri e Hardt é imanente ao social, destina-se a descrever o poder potencial das forças produtivas dentro do Império.
} 
social”, também de uma produção de subjetividade (Negri e Hardt, 2005, p. 101).

A invasão do tempo do trabalho sobre o tempo da vida implica numa mudança de paradigma que exigiria repensar ambos os conceitos, pois o trabalho não se mistura inteiramente à vida sem que ambos mudem de natureza (Lazzarato, 1999, pp. 90-91). Se o lazer torna-se produtivo, dado que o consumo de produtos, serviços e informações durante o tempo livre gera habilidades e conhecimentos de que o capital necessita para permanecer inovando, o que coloca em cheque a "tradicional separação entre o trabalhador e os meios de produção, entre o mundo do trabalho e o mundo da vida" (Cocco, Silva e Galvão, 2003, p. 8), então, diz-nos Negri, deveríamos nos acostumar a pensar no trabalho não como "objeto sociológico", mas como "sujeito político" (Negri, 2010, p. 41). Nesta perspectiva, importa notar que a confluência entre tempo, espaço da vida e trabalho, deslocam as condições de valorização do capital, dado que "o processo de produção não coincide mais com o processo de valorização" (Corsani, 2003, p. 26). Escreve Yann Moulier-Boutang (2003, p. 49):

Com a produção flexível e a queda da sequência montante (produção) / jusante (consumo), nos pós-fordismo, o ato do consumo torna-se uma parte decisiva da produção em tempos reais e em fluxos tensos. Se apenas o que já foi validado pelo mercado e antecipadamente comprado por uma demanda cada vez mais diversificada é produzido, a sociedade não é somente penetrada ex-post pelo mercado e pelo capitalismo, ela intervém ex-ante: a sociedade torna-se um momento produtivo indispensável da empresa global.

Isto sugere que a geração de valor no capitalismo cognitivo não mais dependeria do tempo de trabalho socialmente necessário para a reprodução das mercadorias, e sim da produção do conhecimento pelo próprio conhecimento e da 
exploração direta das relações sociais. Ambos os fatores se encontram em alguma medida atrelados. Claro está que não há novidade alguma em afirmar a importância do conhecimento como força produtiva. A diferença é que atualmente o conhecimento é ao mesmo tempo um recurso e um produto, "desincorporado de qualquer recurso e de qualquer produto", convertendo-se assim na mola mestra do desenvolvimento econômico (Corsani, 2003, p. 26).

Através das possibilidades abertas pelas tecnologias de informação, da comunicação distribuída em rede, o capitalismo pode enfim apropriar-se diretamente do valor produzido socialmente na reprodução da própria vida social. Donde a crescente importância das externalidades, outrora encaradas como tendo apenas um papel marginal na economia (Boutang, 2012). Não mais: pois é através da captação de externalidades que a empresa extrai parte significativa do valor (Gorz, 2010). Para tanto, a empresa deve franquear 210 suas fronteiras e, mimetizando os princípios organizacionais das redes, confundir-se com a cooperação espontânea, apresentar-se sob uma forma fluida, como uma "caixa oca" (Moulier-Boutang, 2003, pp. 42-47). Google, Facebook e Twitter não são sites que produzem conteúdos, mas plataformas que, ao permitirem aos usuários maneiras inteligentes de trocar conteúdos entre si, vendem as informações que coletam sobre eles. No universo gratuito das redes sociais, o próprio usuário é a mercadoria a ser comercializada.

Nesse ponto, a reação usual aos argumentos de Negri e Hardt até aqui examinados consiste em apontar a irrelevância estatística do trabalho imaterial, da produção oriunda do general intellect e das externalidades que lhes estão associadas. Essa, contudo, parece uma crítica insuficiente. Quando Marx afirmava a hegemonia do capitalismo industrial, não estava sugerindo que a maioria das pessoas de fato trabalhava nas fábricas, mas sim que suas formas de mecanização, seus dias de trabalho, suas relações salariais, seus regimes de 
administração do tempo, foram progressivamente sendo impostos aos demais setores produtivos e a vida social como um todo, resultando numa economia e numa sociedade industriais. Da mesma forma, a alegação de que a produção industrial não é mais central na economia capitalista atual, e que em seu lugar residem agora os bens imateriais, não tem caráter quantitativo, e sim qualitativo: as qualidades do trabalho imaterial estão se espraiando, contaminando as demais formas sociais, aos poucos se fazendo dominantes (Hardt, 2009). Mais do que uma realidade empírica, a noção de trabalho imaterial designaria uma tendência, um devir.

Aceito esse caráter tendencial do argumento acerca do trabalho imaterial, ainda assim uma série de questionamentos se impõe. A acumulação capitalista não prosperou justamente por meio de sua capacidade de organizar, ao mesmo tempo, desenvolvimento e subdesenvolvimento? Não foi em função dessas disparidades, da capacidade de transferir riqueza de um polo a outro, que a acumulação pode expandir-se? Se todo o trabalho envolvido na reprodução de seres humanos é cognitivo, no sentido de que produz não apenas coisas, mas "modos de ser", então o que haveria de tão novo no trabalho cognitivo? E o que dizer da expansão ainda em curso do trabalho em condições quase escravagistas, a exploração de crianças e imigrantes ilegais, a precarização absoluta das condições fabris em países pobres?

Quando Caffentzis (2010) levanta estas perguntas é para argumentar que a lógica do capitalismo só pode ser adequadamente compreendida se vista em sua totalidade, observando tanto os pontos mais altos de suas realizações técnicas e científicas, quanto os mais baixos. Daí a necessidade de enxergar a continuidade das lutas através dos diferentes lugares onde elas se dão na divisão internacional do trabalho. Se, ao contrário, postularmos uma hierarquia dentro da qual o trabalho imaterial ocupa posição privilegiada, ofuscaremos todas as importantes particularidades do trabalho no 
capitalismo atual, contribuindo para mantê-las nas sombras, num esquecimento cujo efeito é o silenciamento de suas demandas. Estabelecer uma nova hierarquia de atividades e das formas de acumulação capitalista poderia contribuir para criar uma cisão no ativismo, nas lutas de resistência, obstaculizando a recomposição da noção de classe trabalhadora: lembremos, por exemplo, da surdez de movimentos marxistas tradicionais às demandas do feminismo, porque está supostamente fora do conflito de classes, e da miopia em relação ao campesinato, por não ser considerado fonte de energia revolucionária (Caffentzis e Federici, 2007). Em suma, noções como a de trabalho imaterial e capitalismo cognitivo representam somente uma parte do desenvolvimento capitalista atual. Sua teorização, embora necessária, pode ser lida como a extrapolação ou generalização de uma realidade vivida apenas por homens brancos ricos do Atlântico Norte (Dyer-Witheford, 2001, p. 71) - não por 212 acaso, o lugar de fala de seus autores.

Negri e Hardt invertem o sinal da interpretação da precarização do trabalho, insistindo que, como atividade cognitiva, encontra-se cada vez mais livre do controle e supervisão direta do capital, o que abre espaço para a autonomia e a auto-organização. Pensam no trabalho imaterial como se libertando do capital, e não sendo capturado por ele (Camfield, 2007, p. 35), o que não parece ser o caso, sobretudo se levarmos em consideração a exploração de cunho rentista no capitalismo globalizado. Dessa forma, os autores subestimam o quão supérfluos os trabalhadores estão se tornando devido à automação tecnológica - algo que também os marxistas tradicionais, porque estavam focados na centralidade do trabalho, tiveram dificuldade de perceber (Jappe, 2013) -, ou o papel estrutural que atualmente cumpre o desemprego, o que levou Žižek a afirmar, um tanto ironicamente, que "Negri celebra como a única chance de superar o capitalismo [o que] os ideólogos da 'revolução da informação' celebram como a 
ascensão do novo capitalismo 'sem atrito'” (Žižek, 2012a, p. 19). Mais ainda, Negri e Hardt parecem escrever como se os trabalhadores imateriais, a maioria dos quais pertencentes às altas esferas capitalistas - lembremos que agricultura e indústria ainda respondem por 2/3 do empregos globais -, conformassem uma espécie de vanguarda revolucionária. No entanto, foram os movimentos campesinos que fizeram as revoluções no século XX, durante o período industrial, não os operários; atualmente, são os despossuídos (de terras, de moradias, de empregos, de dignidade) que avançam as lutas contra o capitalismo globalizado (Caffentzis, 2013, p. 122). O trabalho imaterial pode até ser privilegiado em termos da hierarquia capitalista da alta tecnologia, mas a dinâmica de lutas contra-hegemônicas opera em sentido contrário: é o trabalho miserável que gera insurgências espontâneas, o trabalho material que dá a essas insurgências uma forma organizacional (sindicatos, movimentos sociais, greves etc.), e aí sim entra o trabalho imaterial, provendo as imagens e os canais de informação e mídia dentro dos quais as lutas deverão circular (Dyer-Witheford, 2001, p. 77).

Outra linhagem importante de crítica argumenta que a teoria do valor não é anulada pela criação de "mercadorias sem valor" típicas do trabalho imaterial; antes, ela assume uma determinação ainda mais radical ${ }^{6}$ (Paulani, 2016; Teixeira e Rotta, 2012). Paulani (2016, p. 530), por exemplo, observa que o fundamento do preço das mercadorias do setor paradigmático da economia do conhecimento, a informática, é uma "renda do saber, uma renda absoluta, que, tal como a renda absoluta da terra que Marx diagnosticou, fundamenta-se pura e simplesmente na existência da propriedade". Examinando o princípio da autonomização - a tendência, inerente ao capitalismo, das formas sociais de se separarem de suas bases materiais

\footnotetext{
${ }^{6}$ Sigo aqui as observações do parecerista anônimo, a quem agradeço pelas sugestões de literatura sobre o tema.
} 
- no atual capitalismo cognitivo, Teixeira e Rotta assinalam sua condição paradoxal, a "valorização sem valor", isto é, a tentativa do capital de valorizar-se ao mesmo tempo em que busca livrar-se da exploração do trabalho. De acordo com os autores, a análise da produção do conhecimento, que é uma das dimensões desse paradoxo, requer uma apreciação da "mercadoria-conhecimento" (knowledge-commodity), o volume cada vez maior de informações e conhecimento privados, protegidos por novos "cercamentos", como leis de patente e direitos autorais; e "renda-conhecimento" (knowledge-rent), nova forma de rentismo no capitalismo hodierno. O ponto é que "o valor das 'mercadorias-conhecimento sem valor' (valueless knowledge-commodities) não guarda qualquer relação com o valor de uso, e seu sistema de precificação torna-se quase que inteiramente arbitrário" (Teixeira e Rotta, 2012, p. 449, tradução nossa).

Tudo somado, poder-se-ia falar realmente em uma conexão intrínseca entre trabalho imaterial, general intellect 214 e emancipação, tal como assumem Negri e Hardt? Examinar essa questão nos leva ao debate sobre a produção social do comum, ou produção em commons, e é justamente aqui que a aposta dos autores se mostra mais problemática. Na perspectiva do pós-operaísmo, commons não são apenas espaços em que trabalho e vida podem se desenvolver de forma autônoma e sustentável, mas ambientes em que a crítica e a resistência encontram terreno fértil para se desenvolver, dado que pressupõem relações sociais, laços e compromissos que sustentam práticas antagônicas à lógica neoliberal da competição (Hoedemaekers, Loacker e Pedersen, 2012, p. 379). Dito de outro modo, commons são ecossistemas em constante renovação, que só conseguem se manter enquanto tais porque são construídos sobre uma ética do compartilhamento, uma ética hacker (Himanen, 2001). De especial importância seriam os commons informacionais, parte relevante daquilo que Richard Barbrook (1998) chamou de "economia hi-tech da dádiva”, cuja principal característica é a vitalidade das 
atividades não-comerciais que se desenrolam em seu interior. Na medida em que se afiguram como sistemas capazes de criar bases intersubjetivas para modos alternativos de articular a produção social, commons podem ser apropriadamente vistos como a unidade mínima ou célula primitiva do commonismo (Dyer-Witheford, 2010, p. 106). Capitalismo e commonismo são sistemas autopoiéticos - em sua operação, reproduzem também as relações que permitem e garantem sua reprodução - cujos fluxos metabólicos são regulados por dinâmicas que lhes são internas. A diferença é que, ao contrário do capital, commons podem se reproduzir sem que haja crescimento, isto é, sem minar as bases que garantem sua reprodução no tempo (De Angelis, 2013, pp. 607-610).

$\mathrm{O}$ ressurgimento do debate sobre os commons ocorreu devido à confluência de duas perspectivas distintas. De um lado, surge desde uma perspectiva anticapitalista nos anos 1980, tendo suas raízes na crise do socialismo e do nacionalismo do Terceiro Mundo; estrutura-se a partir da crítica ao comunismo, crítica esta que, ao mesmo tempo em que legitimava a si própria através dos sentimentos e comportamentos inerentes ao funcionamento de um commons, acusava a não realização da promessa da livre associação entre os produtores. De outro, o discurso acerca do commons reaparece como uma espécie de "plano B do neoliberalismo", implementado a partir da tentativa de salvar o capitalismo de suas tendências autodestrutivas; neste registro, vem acompanhado de um vocabulário que, unindo noções como "capital social" e "comunidade", pretendia tornar possível ou factível a proposta de outras formas de participação no mercado para além do individualismo e do corporativismo (Caffentzis, 2010, pp. 23-25). Quando o Tratado Norte-Americano de Livre Comércio (NAFTA, em inglês) entra em vigor nos anos 1990, o Banco Mundial começa a explorar as alternativas do commons por meio do Common Property Resource Managment Group (CPRNet), instituição voltada para o fomento de commons com o objetivo não declarado de integrá-los 
posteriormente ao projeto de contrabalancear as tendências destrutivas do neoliberalismo, de forma a tornar o mundo mais seguro para o capitalismo. Tendo flertado com excessos ameaçadores - a "bolha" ponto.com, fraudes contábeis, a explosão da desigualdade, o individualismo predatório -, o capitalismo tardio haveria de engendrar a própria reação, o discurso do "capitalismo responsável”, a afirmação de que em seu interior havia o espaço não-contaminado do comum, permeado pela confiança intersubjetiva e pela horizontalidade, livre da exploração. Não terá sido coincidência que, no momento mesmo em que o projeto neoliberal se afirma em todo o seu extremismo, noções como "capital social", "comunidade" e "confiança" ganham protagonismo (Caffentzis, 2010, pp. 28-31).

Em suma, o capital precisa dos commons para lidar com as contradições que cria - suas estratégias de crescimento intensificam as crises de reprodução ecológica e social, o que lhe obriga a buscar modos alternativos de governança de relações 216 sociais, ou outras formas de sociabilidade para fortalecer sua agenda - tanto quanto os movimentos de resistência precisam confrontar o cercamento dos commons pelo capital (De Angelis, 2013, pp. 606-609). Depois de décadas de governança neoliberal, as desigualdades resultantes são tão pronunciadas, os fracassos tão evidentes, que não podem mais ser escondidos; não é exatamente um acaso que o capital dependa em certa medida de elementos comunistas, como o general intellect, a cooperação e os commons, e que precise fazer uso frequente de seu imaginário (Beverungen, Murtola e Schwartz, 2013, pp. 486487). Mas - e esta é a aposta de Negri e Hardt - o capital não poderia capturar commons sem se deixar infectar. Ao tentar explorá-los, incorporando formas de cooperação para a criação da mais-valia, o capitalismo incubaria práticas econômicas e relações sociais alternativas erigidos por sobre valores éticos que forneceriam as bases não apenas para a crítica das relações econômicas existentes, mas sobretudo para a invenção e consolidação de uma produção social verdadeiramente comum. 
O otimismo inerente a tal aposta se detém tão logo nos damos conta de que a própria cooperação que jaz na raiz da produção social do comum (ou de uma economia da dádiva) pode ser usada em prol da acumulação capitalista, como Marx (2013) já assinalava no capítulo XI do primeiro volume de $O$ Capital. Isso nos obriga a afastar o fetiche da horizontalidade e reconhecer a distinção fundamental entre commons pró-capitalistas, compatíveis com a acumulação do capital, e anticapitalistas, que lhes são antagônicos (Caffentzis, 2010). Mais do que somente uma das engrenagens do trabalho imaterial, a economia da dádiva constitui uma força indispensável ao funcionamento do próprio capitalismo cognitivo. Não faltam exemplos evidenciando que, na economia digital, os lucros são em larga medida produzidos pela inteligência coletiva, dado que é o trabalho espontâneo da multidão que assegura parte da extração da mais-valia (Terranova, 2004, pp. 77-79). A "riqueza das redes", que empreendedores do Vale do Silício elogiam como se implicasse automaticamente mais emancipação e democracia, permanece sendo sequestrada pelo capital, e o lucro é extraído sem que nada seja efetivamente produzido: são as atividades dos usuários que, devidamente rastreadas e classificadas, irão gerar as oportunidades de propaganda que faz o modelo de negócio dos gigantes da internet girar. $\mathrm{Na}$ prática, o general intellect acaba capturado antes de dar ensejo à autonomia, e o destino final da chamada "cultura livre" é a criação de valor privado (Pasquinelli, 2012, p. 60).

A metáfora do parasita é então acionada para dar conta da exploração do trabalho gratuito, colaborativo, feito em rede (Vercellone, 2006 apud Pasquinelli, 2012), e nela a ideia de assimetria é fundamental: jamais a troca entre parasita e hospedeiro é equivalente, dada a apropriação unidirecional. $\mathrm{O}$ parasitismo designaria assim o caráter crescentemente rentista do capitalismo, o "mecanismo nodal da economia contemporânea" (Pasquinelli, 2012, p. 60). Obviamente, o capitalismo 
cognitivo não é apenas parasitário, porque se apropria da força criativa e polinizadora da multidão; continua sendo predador, porque é industrial (Moulier-Boutang, 2012). É nesse sentido que se pode dizer que o compartilhamento de informações e conteúdos, ingrediente fundamental da produção em commons, e que a princípio parece contrariar a expectativa de lucro, converte-se em fonte de extração da mais-valia.

Contudo, ao mesmo tempo em que se aproveita da produção social para extrair renda, o capital prospera através do fechamento cada vez mais acentuado das possibilidades de troca de informações, conhecimentos e produtos culturais. A noção de propriedade intelectual inscreve-se aí como o operador por meio do qual o controle sobre a informação será exercido, na forma de marcas, patentes ou direitos autorais. Ora, os países ricos do Atlântico Norte deram seu salto desenvolvimentista em contextos de baixa proteção de propriedade intelectual; quando suas corporações passaram a deter a maior 218 parte das patentes e dos produtos protegidos por leis, trataram de tornar sua regulação tão rigorosa quanto possível, o que é obviamente prejudicial à nações em desenvolvimento, que importam e consomem tais produtos (Kapczynski, 2010, p. 25). Nesse registro, o Estado desempenha um papel importante não apenas por fornecer o arcabouço legal e político dentro do qual a práxis neoliberal encontra ambiente para prosperar, mas também por intervir diretamente em seu benefício. ${ }^{7}$

\footnotetext{
7 Em 1998 o Digital Millennium Copyright Act (DMCA) já estabelecia restrições para a leitura e empréstimo de livros, inclusive em formato digital. Em 2001, os Estados Unidos começaram a pressionar todos os países do Ocidente a adotar as regras estabelecidas pelo Free Trade of the Americas (FTAA), muitas das quais previstas no DMCA. Mas foi o Agreement on Trade-Related Aspects of Intellectual Property Rights (TRIPS) o grande divisor de águas no controle rigoroso da informação. Até então, países podiam escolher fazer ou não parte da World Intellectual Property Organization (WIPO), entidade que, na prática, não possuía o poder de impor decisões vinculantes ou sanções penais. Assinar o TRIPS era condição para fazer parte da nova World Trade Organization (WTO), que, por dispor um sistema de resolução de disputas, tornava possível fazer com que violações ao tratado fossem a partir de então passíveis de sanções comerciais. A legislação proposta pelo TRIPS era mais abrangente - passou a cobrir recursos naturais, como plantas e raízes -, e impunha penas à pirataria.
} 
Não há, portanto, motivos para supor que iniciativas commonistas, e a economia da dádiva que ajudam a colocar em movimento, tenham condições de sobrepujar a força do capital financeiro globalizado, de modo a dar ensejo às aspirações emancipatórias que Negri e Hardt projetam para o cenário pós-capitalista que têm em mente. É verdade que o fiapo de autonomia que caracteriza o comum, o trabalho cooperativo e espontâneo da multidão, poderia em princípio opor alguma resistência à mercantilização das esferas da vida no contexto neoliberal, instaurando uma dinâmica de fuga (exit) que em alguma medida coloca em questão os imperativos de mercado. Mas não basta a mera aposta - a essa altura, de caráter puramente teórico - de que a consolidação da produção do comum logre por si só abrir a possibilidade de uma nova lógica institucional, em que fluxos de singularidades venham a se transformar em poder constituinte. Não há quaisquer indícios reais de que tal dinâmica possa ser capaz de efetivamente subverter as relações da sociedade com o capital, ou de livrar a política da dominação imposta pelos grandes interesses financeiros. Se a soberania do cidadão vier a prevalecer sobre a soberania do consumidor, o que parece pouco plausível, não terá sido em função do trabalho feito por commons.

\section{Política: anarquia, Estado e utopia}

A ascensão da democracia ao status de único regime político legítimo na contemporaneidade caminhou a par com o crescimento de seu desencanto, o que não surpreende, dadas as insatisfatórias respostas que nações democráticas vêm oferecendo aos desafios que enfrentam. Não será preciso retomar a enorme literatura que documenta as insuficiências e os paradoxos da democracia hodierna; para os propósitos aqui em tela, será suficiente observar que, tomada em seu aspecto substantivo, e não meramente formal, a democracia não parece capaz de cumprir as 
promessas sobre as quais se funda (Agamben, 2004; Bobbio, 1986; Brown, 2011; Žižek, 2012b). Tal diagnóstico acerca das (im) possibilidades da democracia contemporânea é também o de nossos autores. Segundo Negri e Hardt, não restaria alternativa senão reconhecer o fracasso do ideal da representação, dada a erosão da soberania do Estado-nação, deslocada pelo Império. "Quando a soberania nacional é removida pela autoridade de um novo poder supracional, o Império", escreve Negri (2003, p. 120), “a realidade política perde a sua medida. Nessa situação, a impossibilidade de representar o povo torna-se cada vez mais clara, e assim o próprio conceito de povo tende a evaporar-se".

Após tal evaporação, seguir-se-ia a solidificação de um novo sujeito político, a multidão. De inspiração spinozista, a multidão de Negri e Hardt refere-se a um conjunto de singularidades que - contrariamente às noções de "povo" e "massa", entendidas como entidades uniformes e unitárias, 220 que dissolvem as particularidades num todo homogêneo - conformam multiplicidades constituídas por diferenças internas. Tais diferenças, a despeito de não poderem ser reduzidas a uma essência, ainda assim produzem o comum. O conceito de multidão é empregado de duas formas distintas: ontologicamente, como sub species aeternitatis, a multidão sem a qual não se pode conceber o ser social; e historicamente, ou seja, uma multidão política desde sempre latente, mas que só agora estaria começando efetivamente a tornar-se realidade. "Desse modo, quando juntamos as duas, a multidão tem uma estranha temporalidade dupla: sempre-já e ainda-não" (Negri e Hardt, 2005, p. 286). A multidão é ao mesmo tempo um produto do poder, posto que toda produção biopolítica é uma produção de subjetividade, e o excesso que escapa ao próprio poder, assim opondo-lhe resistência criativa. É um "conceito de potência”, que não quer apenas se expandir, mas se corporificar no general intellect e desafiar toda tentativa de representação, justamente 
por se tratar de uma "multiplicidade incomensurável" e irrepresentável (Negri, 2004, p. 17).

Assim sendo, a multidão não poderia ser apreendida em termos contratualistas: não "firma pactos com o soberano" porque é "reativa à obediência" (Virno, 2004b, p. 27), porque sua própria existência solapa o imperativo da representação. Trabalho, afeto, jogos de linguagem, ação coletiva - todas as dimensões da vida social assumem a forma da multidão, são capturados por ela, sem, no entanto, serem passíveis de redução a uma entidade fechada. A produção resultante do comum não surge, portanto, da subordinação de diferenças a uma particularidade que as engloba, mas está fundada na interação e na colaboração entre constituintes singulares. Em chave deleuziana, Negri e Hardt postulam a potência da multidão como alternativa tanto à soberania hegemônica da política moderna, quanto à anarquia pós-moderna de diferenças incomensuráveis: a articulação rizomática deslocaria a lógica binária e antagônica que opõe inclusão à exclusão, identidade à diferença. Quando evocam a multidão, os autores não estão nem a operar por meio de um holismo absoluto, que encerra a agência individual numa totalidade que a engloba e ultrapassa, nem por sobre um atomismo redutor.

A democracia que os autores têm em mente não é nem representativa, nem direta, mas aquela cuja forma política replicaria a lógica e a estrutura da produção social da multidão. "As redes colaborativas sugeririam um arcabouço para uma nova estrutura institucional de sociedade. Essa democracia na qual todos nós criamos e mantemos a sociedade de maneira colaborativa através de nossa produção biopolítica é a que chamamos de 'absoluta'” (Negri e Hardt, 2005, p. 438). Cientes de que sua proposta levanta objeções imediatas incontornáveis - "Mas quem governa? E de que forma prática?" -, Negri e Hardt investem contra o princípio que estruturaria a tradição ocidental de teoria política, o de que 
a unidade ou indivisibilidade do sujeito que governa é um pré-requisito indispensável ao exercício de sua soberania. "Somente o uno pode ser soberano, afirma a tradição, e não pode haver política sem soberania. [...] A alternativa é absoluta: soberania ou anarquia!" (Negri e Hardt, 2005, p. 412). Mas essa seria uma falsa oposição, finalmente desnudada pela ascensão da produção colaborativa e compartilhada como o modo de ser do social: "O poder da multidão de criar relações sociais em comum coloca-se entre a soberania e a anarquia, com isto apresentando uma nova possibilidade de fazer política" (Negri e Hardt, 2005, p. 421). Resta interrogar que possibilidade é essa, quais as formas concretas que assumiria, e os efeitos que colocaria no mundo.

Ao avançarem o conceito de multidão, os autores pressupõem tanto uma ontologia da imanência e da abundância, quanto um automatismo associativo que obscureceria a necessidade de mediações propriamente políticas (Laclau, 222 2007, pp. 240-244). Não nos explicam por quais razões, ou com base em que mecanismos, a multidão não cessa de trocar, compartilhar e colaborar de forma aberta, espontânea e livre de hierarquias. Ao contrário, a lógica da ação integrada e integradora da multidão é desde sempre ontologicamente pressuposta no próprio modo de ser do social. Negri e Hardt pressupõem justamente aquilo que deveriam explicar: falta-lhes uma teoria da ação que pudesse lançar alguma luz sobre as engrenagens que regem a inclinação cooperativa que constitui parte significativa do funcionamento do social. Do mesmo modo, falta também uma teoria da articulação: o que fazer da organização da multidão, da canalização de sua força num projeto concreto? Por meio de que mecanismos institucionais a multidão lograria produzir decisões vinculantes? Os autores dizem quase nada a esse respeito. Quando se põem a tatear os contornos práticos de seu projeto político, o máximo que fazem é indicar, de modo superficial, que ele conformaria uma síntese entre a 
proposta leninista de abolição do Estado e os métodos republicanos defendidos por Madison em O Federalista (Negri e Hardt, 2005).

Não é difícil identificar o caráter antipolítico do argumento. A eliminação de assimetrias entre sujeitos políticos individuais e a comunidade de que são parte é condição para a supressão da necessidade de qualquer forma de representação. Se a vontade geral é expressão da vontade de um sujeito cujos limites coincidem com os da comunidade, então não há necessidade de qualquer mecanismo representativo - e, a rigor, nem da política. Mas se o que existe é um corpo social internamente marcado por divisões e exclusões, a vontade da comunidade como um todo só pode ser politicamente construída a partir de sua própria diversidade. Neste caso, o consenso expresso na vontade geral requer a representação como seu terreno de emergência. Isso sugere que qualquer multidão é construída por meio da ação política, o que, por sua vez, pressupõe algum dado de antagonismo (Laclau, 2004, p. 25).

Negri reconhece a validade do ceticismo que seus críticos lhe endereçam, mas afirma, evocando Hirschman, que a resistência da multidão trabalharia por meio de sua tendência ao êxodo (exit), isto é, a recusa a tomar parte numa ordem ou realidade estabelecida como elemento que sabota sua autorreprodução (Negri, 2009, pp. 22-29). Contudo, se a atividade política pode ser encaminhada por dinâmicas autopropulsoras, intrinsecamente virtuosas, então por que dedicar tempo e esforço a fim de teorizar sobre estruturas e conjunturas, ou lidar com as sempre difíceis questões de associação? (Kioupkiolis, 2010, p. 143). Negri e Hardt derivam do pan-relacionismo ontológico de inspiração deleuziana um sujeito político cuja constituição e modo de funcionamento seriam intrinsecamente harmônicos, não-conflituosos. Eis o contrassenso: se a condição de possibilidade do político é, por definição, a dimensão de 
antagonismo que o constitui, então o exercício de imaginar uma política livre do contraditório e do dissenso assinala a esperança da efetivação daquilo que Žižek (2006) chamou de arquipolítica, a tentativa de reificar um espaço social idealmente homogêneo, estruturalmente fechado, que interdita de antemão a possibilidade do surgimento do próprio acontecimento político.

Veremos mais adiante outras observações acerca de tal pressuposto ontológico. Por ora, voltando ao terreno da empiria, seria o caso de observar o fato de que lutas de resistência ou movimentos contra-hegemônicos não necessariamente conformam um todo harmônico. Negri e Hardt desconsideram, por exemplo, que o melhoramento radical das condições no Sul implicaria em sacrifícios ao Norte desenvolvido, ou que as demandas por equidade global se chocam com as demandas ecológicas (Dyer-Witheford, 2001, p. 75). Tudo se passa como se singularidades dispersas, muitas das 224 quais subalternas, pudessem subitamente se coadunar em movimentos rizomáticos capazes de deslocar, como num passe de mágica, todas as assimetrias, as exclusões, as contradições, os dissensos, os silenciamentos que as atravessam e constituem. Postular a multidão como um sujeito político de vanguarda que, por suas qualidades intrínsecas, estaria em posição de produzir uma resistência que deflagraria a emergência da democracia absoluta, é uma tentativa de solucionar por via exclusivamente teórica questões difíceis, exigentes, cujo exame não pode prescindir de um olhar atento ao movimento concreto das coisas do mundo (Dowling, Nunes e Trott, 2007, pp. 5-6).

A bem da verdade, entretanto, é preciso reconhecer que Negri e Hardt escrevem com o objetivo de avançar uma filosofia política capaz de restaurar a fé numa utopia democrática e socialista, não oferecer uma descrição detalhada de como implementá-la. Daí podemos enxergá-los mais como profetas interessados em imaginar um devir do que como 
críticos preocupados em examinar a realidade que têm diante de si (Graeber, 2011, p. 13). Assim sendo, para além da crítica acima mobilizada, seria preciso enfrentar as ideias dos autores em seu próprio terreno, isto é, interrogar a utopia que têm em mente, os possíveis que desejam construir.

Como todo exercício de imaginação utópica, a multidão negriana arremessa o pensamento para fora de suas fronteiras atuais, pretendendo converter-se em instrumento de introdução de novos vocabulários. Mas, também como toda utopia, a multidão é sobretudo uma fantasia que, ao lutar para negar o negativo que atravessa a atual realidade política, pretende-se uma resposta definitiva para os antagonismos que a constituem. Parafraseando Yannis Stavrakakis (1999, p. 99), poder-se-ia dizer que a multidão é a imagem projetada de uma futura comunidade na qual tais antagonismos - o elemento propriamente político do social - estariam para sempre resolvidos, dando ensejo a um mundo reconciliado, harmonioso. Utopias apresentam uma resolução imaginária para contradições sociais reais; nesse sentido, são simulacros referidos à presença de um outro indesejado. Isso sugere que, para se constituir, toda utopia precisa eleger um arqui-inimigo, um "bode expiatório", para então perspectivar um futuro livre de sua existência. Aí o paradoxo: sendo a realização concreta de sua fantasia salvacionista ou redentora sempre necessariamente adiada, o discurso utópico poderá conservar seu poder e influência somente se atribuir essa impossibilidade a um outro cuja presença faz germinar um desconforto, uma inquietude (Stavrakakis, 1999, pp. 107-111).

O inimigo, o antagonista da qual a fantasia utópica da multidão depende para constituir-se, e cuja eliminação assinalaria seu triunfo final, é a forma-estado tal como a conhecemos atualmente. Em termos estruturais, é o arcabouço jurídico-político do Estado que garante sustentação ao complexo de instituições financeiras, organismos de governança 
internacionais e megacorporações transnacionais que conformam o Império. A multidão é notadamente anticapitalista, por certo, mas a soberania cuja desconstrução Negri e Hardt afirmam ser indispensável à efetivação da democracia absoluta é sustentada e atualizada pelo Estado e suas instituições. Nesse sentido, os autores partilham com pensadores liberais a certeza de que o elemento transcendente da soberania opera como um mecanismo de usurpação da legitimidade imanente do demos (Ribeiro, 2014, pp. 180-181). Logo, a democracia absoluta não poderia realizar-se enquanto perdurar o Estado - mas não é precisamente essa a utopia tanto do anarquismo quanto do marxismo tradicional? Onde, então, residiria a especificidade da utopia negriana?

A diferença ontológica entre a multidão de singularidades e o sujeito político do anarquismo é claramente delineada. Não há, como no anarquismo, o pressuposto maniqueísta de uma essência humana naturalmente boa, que o 226 poder do Estado viria corromper. Negri e Hardt concordam com Stirner e Foucault quanto ao fato de que o poder não é instância monolítica que opera verticalmente, reprimindo o indivíduo, mas um conjunto de dispositivos que o constitui. Contudo, se por um lado os autores não partem de um fundamento natural que os permita condenar o poder como imoral ou aviltante ao homem, por outro assumem como dado que a multidão se constitui essencialmente como figura de resistência. A multidão seria animada por um desejo revolucionário entendido à maneira de Deleuze, isto é, uma concepção a-histórica e metafísica de desejo, inerentemente revolucionária, criativa e produtiva, e não manipulada ou reprimida (Newman, 2007, p. 109). Nesse ponto, todo o argumento de Negri e Hardt depende da ideia de pureza para permanecer de pé: é essa noção universal de desejo, intocada pelo poder e por isso mesmo naturalmente revolucionária, que possibilita aos autores postular um lugar essencial de resistência. Ao fim e ao cabo, a fantasia 
da multidão repete o anarquismo clássico, no sentido de imaginar que o poder político tenha um exterior a partir do qual haveria de ser criticado e superado.

Este exterior não conspurcado pelo poder, lugar de uma pureza revolucionária, obedece a um princípio de funcionamento cooperativo, voluntário, harmonioso. Mas princípios não trazem incrustados em si a regra de sua aplicação. O mesmo princípio político pode dar ensejo a diferentes modelos institucionais e práticas específicas erigidas em seu nome. Postular a abolição do Estado como condição de possibilidade da realização da verdadeira democracia nada diz sobre possíveis transformações correspondentes no modo de produção ou nas formas institucionais político-sociais. Negri e Hardt apostam na realização de uma espécie de anarcocomunismo - sem o Estado a sustentar o Império, a produção cooperativa do comum operada pela multidão enfim encontraria condições para florescer. Simplesmente assumem como certo tal destino, desconsiderando as muitas evidências que apontam em sentido contrário. Então não sabemos que o capitalismo incorporou as críticas e reivindicações feitas no bojo do Zeitgeist contracultural que irrompe a partir da segunda metade do século passado, apenas para transformá-las em fonte de potência (Boltanski e Chiapello, 2009)? Não testemunhamos a reivindicação pelo fim do salário fixo converter-se no elogio da precariedade empreendedora, a crítica da alienação e a demanda pela valorização da singularidade transformar-se na celebração da diversidade de identidades de consumo, um culto fetichista das diferenças (Virno, 2004a)? Não vimos que o capitalismo tardio, predador e parasita, vem sendo bem-sucedido em transformar produção social em lucro privado? Não dispomos já de suficientes exemplos de que a exploração do comum por meio de operações de cunho rentista serve mais aos interesses do capital do que daqueles que se lhe opõem? Se os indícios até aqui sugerem um provável desfecho para a utopia de 
uma democracia funcional sem Estado, não será o anarcocomunismo, e sim o anarcocapitalismo ${ }^{8}$. Supor que o capitalismo venha a desmanchar-se no ar tão logo a forma-estado cesse de existir, é acreditar que perderia, como num passe de mágica, sua capacidade de metamorfosear-se, de aproveitar-se da destruição criativa para refazer a si próprio.

\section{Considerações finais}

Não é difícil compreender as razões pelas quais o ativismo contra-hegemônico contemporâneo encontra inspiração na obra de Negri e Hardt. O descrédito generalizado nas possibilidades da democracia, vista ora como engenharia política sequestrada por interesses econômicos, ora como mero cálculo eleitoral autorreferido, aliada à sensação de impotência de indivíduos perante forças sistêmicas implacáveis, sedimenta um terreno propício ao tipo de solução que Negri e Hardt oferecem. Contra a espoliação do trabalho no capitalismo tardio, a força colaborativa do comum; contra a usurpação da soberania popular pela democracia liberal, a potência constituinte da multidão autônoma.

Entretanto, vimos boas razões para afirmar que nem a força colaborativa do comum, nem a potência constituinte da multidão parecem ser soluções satisfatórias para as insuficiências dos atuais sistemas democráticos. Conforme argumentamos, a produção em commons, a despeito do ethos anticapitalista que lhe subjaz, permanece em larga medida sendo apropriada pelo capital; mais ainda, o exame do estatuto do trabalho imaterial sugere não haver qualquer

\footnotetext{
${ }^{8}$ Seria interessante verificar as afinidades eletivas entre as obras de autores clássicos do anarcocapitalismo e as formulações de Negri e Hardt. Para ficarmos apenas em dois exemplos: a sociedade que Murray Rothbard (1998) tinha em mente, fundada no princípio da não-agressão, caracterizava-se justamente pela ação voluntária, livre de qualquer espécie de coerção por parte de um poder centralizado; e mesmo David Friedman (1973), em que pese o utilitarismo que informa sua perspectiva, reconhece a importância de arranjos comunitários para a saúde de um tecido social que não conhece a autoridade do Estado.
} 
espécie de conexão direta entre o general intellect e as aspirações emancipatórias que Negri e Hardt alimentam. Do mesmo modo, constatamos as fragilidades constitutivas da aposta dos autores na agência da multidão, o sujeito político a quem caberia a tarefa de realizar, pela cooperação e livre compartilhamento, a democracia absoluta. Daí falarmos numa utopia neoanarquista: as ideias de Negri e Hardt apresentam as mesmas inconsistências que suas antecessoras no anarquismo clássico, mas transbordam a certeza de que produziriam resultados diferentes (e virtuosos), caso viessem a se efetivar concretamente. Ao não descer aos detalhes empíricos de suas formulações, permanecendo deliberadamente no conforto teórico das abstrações, Negri e Hardt logram produzir ressonância e encantamento. O preço pago por essa operação, no entanto, afigura-se problemático, para dizer o mínimo.

Poder-se-ia retrucar que, se as ideias dos nossos autores não têm lugar no mundo atual, isso ainda assim não invalidaria a sua formulação. É verdade, mas não se trata de pedir a Negri e Hardt uma ciência política que sua filosofia não se propõe a fornecer. Que o pensamento não seja obrigado a demonstrar sua viabilidade factual, que esteja livre para projetar utopias para além dos vocabulários aceitos de seu tempo, é algo que está fora de questão. Isso, contudo, não deveria eximir os autores de preocuparem-se com o tipo de esperança que sua imaginação utópica pode gerar, e o tipo de frustração decorrente de sua não realização.

\section{Antonio Claudio Engelke Menezes Teixeira}

é doutor em Ciências Sociais pela Pontifícia Universidade Católica do Rio de Janeiro (PUC-Rio). Atualmente conclui pós-doutorado PNPD/Capes em Ciência Política na Uerj. Tem artigos publicados em diversos periódicos científicos e em veículos de comunicação como a revista Piauí e o jornal $O$ Globo. Coeditou, ao lado de Wilson Gomes e Fernando 
Lattman-Weltman, o volume Política da coleção Ensaios Brasileiros Contemporâneos (Funarte).

\section{Bibliografia}

AGAMBEN, Giorgio. 2004. Estado de exceşão. São Paulo: Boitempo.

BARBROOK, Richard. 1998. The hi-tech gift economy. First Monday, v. 3, n. 12, 7 Dec. 1998. Disponível em: https://bit.ly/31aKmpv. Acesso em: 14 ago. 2011.

BEVERUNGEN, Armin; MURTOLA, Anna-Maria; SCHWARTZ, Gregory. 2013. The communism of capital? Ephemera: theory $\mathcal{E}^{\circ}$ politics in Organization, v. 13, n. 3, pp. 483-495.

BOBBIO, Norberto. 1986. O futuro da democracia: uma defesa das regras do jogo. Rio de Janeiro: Paz e Terra.

BOLTANSKI, Luc; CHIAPELLO, Eve. 2009. O novo espírito do capitalismo. São Paulo: Martins Fontes.

BROWN, Wendy. 2011. We are all democrats now... In: AGAMBEN, Giorgio; BADIOU, Alain; BENSAID, Daniel; BROWN, Wendy; NANCY, Jean-Luc; RANCIÈRE, Jacques; ROSS, Kristin; ŽIŽEK, Slavoj. Democracy in what state? New York: Columbia University Press. pp. 44-57.

CAFFENTZIS, George. 2010. The Future of "The Commons":

Neoliberalism's "Plan B" or The Original Disaccumulation of Capital? New Formations, n. 69, pp. 23-41. Disponível em: https://bit. ly/316R5AL. Acesso em: 1 ago. 2019.

CAFFENTZIS, George; FEDERICI, Silvia. 2007. Notes on the Edu-factory and Cognitive Capitalism. eipcp. Disponível em: http:/ /eipcp.net/ transversal/0809/caffentzisfederici/en. Acesso em: 2 set. 2012. [O link está não mais acessível].

CAMFIELD, David. 2007. The multitude and the kangaroo: a critique of Hardt and Negri's theory of immaterial labour. Historical Materialism, v. 15, n. 2, p. 21-52.

COCCO, Giuseppe; SILVA, Gerardo; GALVÃO, Alexander Patez. 2003. Introdução: conhecimento, inovação e redes de redes. In: COCCO, Giuseppe; SILVA, Gerardo; GALVÃO, Alexander Patez (org.). Capitalismo cognitivo: trabalho, redes e inovação. Rio de Janeiro, DP\&A. pp. 7-14.

COLLETTI, Lucio. 1972. From Rousseau to Lenin: studies in ideology and society. New York: New Left Books.

CORSANI, Antonella. 2003. Elementos de uma ruptura: a hipótese do capitalismo cognitivo. In: COCCO, Giuseppe; SILVA, Gerardo; GALVÃO, Alexander Patez (org.). Capitalismo cognitivo: trabalho, redese inovação. Rio de Janeiro, DP\&A. pp. 15-32. 
DAWSON, Ashley. 2010. Introduction: new enclosures. New Formations, n. 69 , pp. 8-22.

DE ANGELIS, Massimo. 2013. Does capital need a commons fix? Ephemera: theory $\mathcal{E}$ politics in organization, v. 13, n. 3, pp. 603-615.

DOWLING, Emma; NUNES, Rodrigo; TROTT, Ben. 2007. Immaterial and Affective Labour: explored. Ephemera: theory $\mathcal{E}$ politics in organization, v. 7, n. 1, pp .1-7.

DYER-WITHEFORD, Nick. 2001. Empire, immaterial labour, the new combinations, and the global worker. Rethinking Marxism, v. 13, n. 3/4, pp. $70-80$.

DYER-WITHEFORD, Nick. 2010. Commonism. In: TURBULENCE COLLECTIVE. What would it mean to win? Oakland: PM Press. pp. 105-112.

FRIEDMAN, David. 1973. The Machinery of Freedom: guide to a radical capitalism. Chicago: Open Court Publishing Company. Disponível em: https://bit.ly/1fMuIC1. Acesso em: 17 jul. 2015.

GRAEBER, David. 2011. Debt: the first 5000 years. New York: Melville House. GRANOVETTER, Mark. 1973. The strength of weak ties. American Journal of Sociology, v. 78, n. 6, pp. 1360-1380.

GORZ, André. 2010. The Immaterial: knowledge, value and capital. London: Seagull Books.

HARDT, Michael. 6 July 2009. Politics of the common. ZCommunications.

Disponível em: https://bit.ly/334s9vD. Acesso em: 24 abr. 2012.

HIMANEN, Pekka. 2001. The hacker ethic and the spirit of the information age.

New York: Random House.

HOEDEMAEKERS, Casper; LOACKER, Bernadette; PEDERSEN, Michael. 2012. The commons and their im/possibilities. Ephemera: theory $\mathcal{E}^{2}$ politics in organization. v. 12, n. 4, pp. 378-385.

JACOBY, Russell. 2001. O fim da utopia: política e cultura na era da apatia. São Paulo: Record.

JAPPE, Anselm. 5 ago. 2013. A perplexidade da esquerda. O Povo.

Disponível em: https://bit.ly/2yui3Gj. Acesso em: 13 ago. 2013.

KAPCZYNSKI, Amy. 2010. Access to knowledge: a conceptual genealogy.

In: KAPCZYNSKI, Amy; KRIKORIAN, Gaëlle (ed.). Access to knowledge in the age of intellectual property. Brooklin: Zone Books. pp. 17-56.

KIOUPKIOLIS, Alexandros. 2010. Radicalizing democracy. Constellations, v. 17 , n. 1, pp. 137-154.

LACLAU, Ernesto. 2004. Can immanence explain social struggles? In: DEAN, Jodi; PASSAVANT, Paul (ed.). Empire's new clothes: reading Hardt and Negri. New York: Routledge. pp. 21-30.

LACLAU, Ernesto. 2007. On populist reason. London: Verso. 
LATOUR, Bruno. 2012. The whole is always smaller than its parts: a digital test of Gabriel Tarde's Monads. British Journal of Sociology, v. 63, n. 4, pp. 591-615.

LAZZARATO, Maurizio. 1999. Para uma definição do conceito de biopolítica. Lugar Comum. n. 5-6, pp. 81-96.

LESSA, Sérgio. 2001. Trabalho imaterial: Negri, Lazzarato e Hardt. Estudos de Sociologia, v. 6, n. 11, pp. 119-143.

MARX, Karl. 2013. O Capital: crítica da economia política. Rio de Janeiro: Civilização Brasileira. Livro I.

MEZZADRA, Sandro. 23 out. 2013. O que é operaísmo italiano.

Universidade Nômade Brasil. Disponível em: https://bit.ly/2qmeVa9. Acesso em: 25 out. 2013.

MOULIER-BOUTANG, Yann. 2003. O território e as políticas de controle do trabalho no capitalismo cognitivo. In: COCCO, Giuseppe; SILVA, Gerardo; GALVÃO, Alexander Patez. (org.). Capitalismo cognitivo: trabalho, redes e inovação. Rio de Janeiro: DP\&A. pp. 33-60.

MOULIER-BOUTANG, Yann. 2012. Revolução 2.0, comum e polinização. In: COCCO, Giuseppe; ALBAGLI, Sarita (org.). Revolução 2.0 e a crise do capitalismo global. Rio de Janeiro: Garamond. pp.75-93.

232 NEGRI, Antonio. 2003. Cinco lições sobre Império. Rio de Janeiro: DP\&A.

NEGRI, Antonio. 2004. Para uma definição ontológica da Multidão. Lugar Comum, n. 19-20, pp. 15-26.

NEGRI, Antonio. 2009. Conferência de abertura no Fórum Livre do Direito Autoral. Lugar Comum, n. 28, pp. 15-27.

NEGRI, Antonio. 2010. É possível ser comunista sem Marx? Lugar Comum, n. 31, pp. 33-41.

NEGRI, Antonio; HARDT, Michael. 2005. Multidão: guerra e democracia na era do Império. Rio de Janeiro: Record.

NEWMAN, Saul. 2007. From Bakunin to Lacan: anti-authoritarianism and the dislocation of power. Lanham: Lexington Books.

PASQUINELLI, Matteo. 2012. A ideologia da cultura livre e a gramática da sabotagem. In: BELISARIO, Adriano; TARIN, Bruno (org.). Copyfight: pirataria $\mathcal{E}^{2}$ cultura livre. Rio de Janeiro: Beco do Azougue.

PAULANI, Leda Maria. 2016. Acumulação e rentismo: resgatando a teoria da renda de Marx para pensar o capitalismo contemporâneo. Revista de Economia Política, v. 36, n. 3, pp. 514-535.

RIBEIRO, Gustavo. 2014. Modos de soberania e a questão do poder na teoria política contemporânea. Tese de Doutorado em Estudos Sociais e Políticos. Rio de Janeiro: Uerj. 
RORTY, Richard; NYSTROM, Derek; PUCKETT, Kent. 2006. Contra os patrões, contra as oligarquias: uma conversa com Richard Rorty. São Paulo: Editora Unesp.

ROTHBARD, Murray. 1998. The ethics of liberty. New York: New York University Press. Disponível em: https://bit.ly/2XWaaUX. Acesso em: 1 ago. 2015.

STAVRAKAKIS, Yannis. 1999. Lacan and the political. New York: Routledge. TEIXEIRA, Rodrigo; ROTTA Tomas. 2012. Valueless knowledge commodities and financialization: productive and financial dimensions of capital autonomization. Review of Radical Political Economics, v. 44, n. 4, pp. 448-467.

TERRANOVA, Tiziana. 2004. Network culture: politics for the information age. London: Pluto Press.

TRONTI, Mario. 1963. Social capital. Zerowork. Disponível em: https:/ / bit. ly/2GH2Vd1. Acesso em: 21 out. 2012.

TROTT, Ben. 2007. Immaterial labour and world order: an evaluation of a thesis. Ephemera: theory $\mathcal{E}^{\mathcal{O}}$ politics in organization, v. 7, n. 1, pp. 203-232.

VIEIRA, Zaira. 2007. Para uma crítica do trabalho imaterial. Paper apresentado no V Colóquio Internacional Marx e Engels do Centro de Estudos Marxistas, Campinas, 6 a 11 de setembro. Disponível em: https://bit.ly/2Kikp0p. Acesso em: 3 out. 2012.

VIRNO, Paolo. 2004a. A Grammar of the multitude: for an analysis of contemporary forms of life. New York: Semiotext(e).

VIRNO, Paolo. 2004b. Multidão e princípio de individuação. Lugar Comum, n. 19, pp. 27-40.

ŽIŽEK, Slavoj. 2006. Elogio da intolerância. Lisboa: Relógio D’água. ŽIŽEK, Slavoj. 2012a. O ano em que sonhamos perigosamente. São Paulo: Boitempo.

ŽIŽEK, Slavoj. 2012b. O violento silêncio de um novo começo. In: HARVEY, David; DAVIS, Mike; ŽIŽEK, Slavoj; ALI, Tariq; SAFATLE, Vladimir et al. Occupy: movimentos de protestos que tomaram as ruas. São Paulo: Boitempo; Carta Maior. pp. 15-26. 


\section{A UTOPIA ANTIPOLÍTICA DE NEGRI E HARDT}

\section{ANTONIO CLAUDIO ENGELKE MENEZES TEIXEIRA}

Resumo: Este trabalho tem por objetivo criticar a sociologia e a política de Negri e Hardt. Do ponto de vista sociológico, o exame dos movimentos de captura do comum por mecanismos rentistas do capitalismo tardio sugere ser infundada a aposta dos autores no potencial emancipatório da dinâmica de êxodo supostamente instaurada pela produção comum. Do ponto de vista político, trata-se de interrogar a projeção utópica da multidão como sujeito político revolucionário a quem caberia a tarefa de realizar a democracia absoluta. A fantasia anarquista de Negri e Hardt não apenas repete o purismo de seus predecessores clássicos, como também se mostra inconsciente de que sua materialização redundaria numa espécie de anarcocapitalismo, não no socialismo democrático imaginado pelos autores.

Palavras-chave: Multidão; Democracia; Trabalho Imaterial; Anarquismo.

\section{THE ANTIPOLITICAL UTOPIA OF NEGRI AND HARDT}

Abstract: Negri and Hardt's success among the new political activism calls for a critical assessment of their sociology and politics. From a sociological perspective, we shall argue that a critical evaluation of the capture of the commons by late capitalism's financial mechanisms suggests that the authors' belief in an emancipatory potential of multitude's cooperative production is flawed. From a political standpoint, we will examine the assumptions and effects of the utopic projection of the multitude as a revolutionary political subject whose task consists in realizing the “absolute democracy". The authors' anarchic fantasy reenacts classic and naive anarchist idea of purity, remaining blind to the fact that its actual realization would pave the way for anarcho-capitalism, rather than the democratic socialism they dreamed of.

Keywords: Multitude; Democracy; Immaterial Labor; Anarchism.

Recebido: 29/03/2016 Aprovado: 12/11/2018 